\title{
PREVENÇÃO AO SUICÍDIO NA ATENÇÃO PRIMÁRIA DE SAÚDE NO MUNICÍPIO DE CASCAVEL - PR
}

\author{
Anderson Henrique Carboni ${ }^{1}$ \\ ${ }^{1}$ Assistente Social Residente em Saúde da Família, Escola de Saúde Pública Municipal ESPM- \\ SESAU, Cascavel, Paraná.
}

DOI: $10.47094 /$ ICONRES.2021/13

\begin{abstract}
RESUMO
Em escala global, o suicídio apresenta-se um grave problema de saúde pública. De acordo com dados divulgados pela Organização Mundial de Saúde (OMS, 2019), um óbito suicida ocorre a cada 40 segundos no mundo. Neste ranking, de acordo com o Ministério da Saúde (2018), o Brasil ocupa o $8^{\circ}$ lugar contabilizando 11 (onze) mil casos de óbitos suicidas. Mesmo diante de tal gravidade, o suicídio é percebido como um grande tabu dentro da sociedade, caracterizando-se, assim, um grande desafio para os profissionais de saúde, em especial para os atuantes na atenção primária, haja vista a proximidade das equipes com a população. Sendo assim, desenvolveu-se um projeto de orientação aos profissionais atuantes das equipes de saúde da família do Município de Cascavel - PR, que traz informações sobre o suicídio, objetivando orientar para o reconhecimento de pacientes em risco, cooperando assim, para prevenção dos casos.
\end{abstract}

PALAVRAS-CHAVES: Saúde Mental; População Adscrita; Educação Permanente.

ÁREA TEMÁTICA: Educação em Saúde

\section{INTRODUÇÃO}

Em linhas gerais, define-se o suicídio como o ato de óbito auto infligido, deliberado e executado pelo indivíduo, utilizando-se de método considerado fatal pelo mesmo, cujo objetivo é morrer. Este desejo é consciente e proposital, ainda que cercado de ambivalência. (CVV, 2014). Por ser um fenômeno complexo e cercado de tabus, muitas vezes é difícil detectar a ideação suicida, evitando assim que o manejo correto dos pacientes com esta intenção seja realizado, em especial nos estabelecimentos caracterizados como portas de entradas, sendo o projeto citado desenvolvido para as unidades de Atenção Primária de Saúde - APS. Este conjunto é composto principalmente pelas Unidades de Saúde da Família (USF) e Unidades de Básicas de Saúde (UBS), que contam com equipes multidisciplinares, sendo elas as instâncias mais próximas dos indivíduos, desempenhando, 
portanto, papel fundamental junto à população. Dessa forma, diversos pacientes buscam suas unidades de referência para pedir ajuda. Todavia, em razão dos estigmas entorno do suicídio, diversos dos profissionais atuantes não possuem instruções suficientes para abordar a temática de forma assertiva. Isto posto, buscando contribuir para o acolhimento humanizado dos pacientes em sofrimento psíquico, desenvolveu-se um projeto de orientação para os profissionais da atenção primária, que objetiva levar informações sobre a temática do suicídio, expondo suas complexidades - fatores de risco, mitos e verdades, posvenção do suicídio, etc. - e como abordar corretamente os pacientes com pensamentos de morte e ideação suicida, cooperando assim, para prevenção dos casos e na oferta de bem-estar para os pacientes atendidos pela equipe.

\section{METODOLOGIA}

Para desenvolvimento do projeto, utilizou-se da pesquisa bibliográfica nos materiais disponibilizados pelo Conselho Federal de Medicina (CFM), Ministério da Saúde e Centro de Valorização da Vida (CVV), pelos quais são grandes referências da temática. A pesquisa resultou no desenvolvimento de uma cartilha de orientação destina aos profissionais da Atenção Primária.

Em relação à aplicação do projeto, utilizou-se a dinâmica de grupos com os profissionais das unidades intervindas. Em decorrência do quadro pandêmico causado pelo SARS COV2 (COVID-19), ficou proibida a realização de reuniões com grandes aglomerações. Dessa forma, para viabilidade da intervenção, dividiu-se os profissionais em pequenos grupos, buscando abranger o máximo do público alvo, mas mantendo todas as medidas sanitárias e de saúde exigidas pelo momento. Por sua vez, a cartilha criada, serviu como guia para realização dos grupos, a mesma deu enfoque na atuação da atenção primária frente às situações envolvendo o suicídio e a importância do acolhimento humanizado para preservação da vida.

Nos grupos, desenvolveu-se uma linha do tempo com os pontos de essencial importância para sensibilização dos profissionais, sendo eles: definição de suicídio; saúde mental e os principais transtornos mentais relacionados ao suicídio; mitos e verdades, buscando desmistificar os mitos mais comuns acerca do tema; o papel da atenção primária de saúde na prevenção dos casos; questões norteadoras para escuta qualificada dos pacientes com adoecimento mental; posvenção do suicídio e os efeitos do luto no familiares; formas de ajudar alguém com pensamento de morte e ideação suicida.

Objetivando, também, atingir o maior número de profissionais com o conhecimento do tema, buscou-se adaptar as linguagens utilizadas dos materiais de referência para uma linguagem mais acessível dentro da cartilha criada para o projeto, de forma que a transmissão do conhecimento pudesse acontecer de modo abrangente. Sendo assim, as informações necessárias puderam ser compreendidas pelos profissionais de nível fundamental, médio, técnico e superior, sem distinção. Posteriormente, ao fim das intervenções, a cartilha foi disponibilizada aos profissionais para estudos e aprofundamento do tema. 
Até o presente momento, o projeto foi desenvolvido em 2 (duas) USFs, 1 (uma) UBS e realizado 1 (um) encontro com os assistentes sociais integrantes do Programa de Residência Multiprofissional em Saúde da Família do Município de Cascavel - PR. Ao todo, foram realizados 9 (nove) encontros entre os meses de agosto a dezembro de 2020.

\section{FUNDAMENTAÇÃO TEÓRICA}

A Política Nacional de Atenção Primária, estabelecida pela Portaria No 2.436/2017, é caracterizada como um conjunto de ações no âmbito coletivo e individual, que visam à promoção, divulgação, prevenção, redução de danos, além de cuidados paliativos e de recuperação da saúde, pelas quais possam abranger os diversos aspectos presentes no conceito de saúde, indo além do simples tratamento de enfermidades. Tudo isso se dará em conjunto com uma gestão qualificada, realizada por equipe multiprofissional, sendo as atividades direcionadas para população adscrita do local. (BRASIL, 2017).

Todas estas atividades precisam ser desenvolvidas com o maior grau de capilaridade, objetivando atender as diligências encontradas em cada área de abrangência. (BRASIL, 2017). Para que este objetivo seja atendido, a política é regida por princípios norteadores que desenham as intervenções, sendo eles os: "da universalidade, da acessibilidade, do vínculo, da continuidade do cuidado, da integralidade da atenção, da responsabilização, da humanização, da equidade e da participação social." (Brasil, 2017, p. 19). Sendo assim, a atenção primária se expressa como grande porta de entrada das demandas, além de ser a instância central de comunicação com a Rede de Atenção em Saúde - RAS, servindo de referência para pacientes e profissionais.

A ênfase na atenção primária em saúde, posta como campo central do projeto, busca reforçar os princípios norteadores da política e aproximar as equipes de saúde da família com a problemática do suicídio, que tem apresentado urgência em seu debate. De acordo com a OMS (2000), a atenção primária em saúde é capaz de ofertar cuidado continuado aos usuários, dispondo de acolhimento para pacientes e familiares dos pacientes, além de organizações e instituições voltadas para temática do suicídio, se tornando assim, campo rico para desenvolvimento de intervenções na temática.

O suicídio é considerado um comportamento caracterizado pelo desejo da própria morte, induzindo o indivíduo a autoaniquilação. Pode ser definido, ainda, como um fenômeno complexo, pois envolve uma série de violências autoinfligidas ao nível psicológico e físico, podendo haver um desfecho trágico. (UNASUS, 2020). Uma das formas mais eficazes de se evitar um desfecho trágico é a detecção precoce dos sinais de alerta emitidos pelo paciente e o correto manejo da situação, de forma que seja possível tratar as causas de cada indivíduo e oferecer bem-estar emocional, físico e social, afastando-o do risco. (ONU, 2015). A OMS (2000) também ressalta que a intervenção de profissionais junto às comunidades, realizando a conscientização de vizinhos, amigos e familiares do indivíduo com ideação suicida, é de grande eficácia para prevenção, uma vez que reforça a rede de apoio pessoal. 


\section{CONSIDERAÇÕES FINAIS}

$\mathrm{Na}$ realização dos grupos, os profissionais participaram e se envolveram bastante com a temática, de modo que a metodologia proposta foi alcançada com êxito, levando, assim, o conhecimento necessário proposto para equipe. Além disso, nos encontros, por vezes, os profissionais compartilharam experiências pessoais envolvendo situações de suicídio com pessoas próximas, ou então, o seu próprio adoecimento mental, enriquecendo os momentos de debate e sensibilizando os profissionais para os problemas da própria equipe.

Sensibilizar a equipe para temática do suicídio também apresentou resultados no cotidiano de trabalho das unidades. Os profissionais deram feedbacks, ou, então, trocaram informações entre si, quando perceberam pacientes com sinais de alerta, possibilitando realizar intervenções com os mesmos e aliviar o sofrimento psíquico destes.

Por fim, vale ressaltar que se pretende continuar realizando os grupos em outras unidades de saúde, auxiliando as equipes e contribuindo para prevenção do suicídio.

\section{PRINCIPAIS REFERÊNCIAS}

BRASIL. PORTARIA No 2.436, DE 21 DE SETEMBRO DE 2017. Política Nacional de Atenção Básica. 2017, Brasília, DF, Diário Oficial. Disponível em: < https://bvsms.saude.gov.br/bvs/saudelegis/ gm/2017/prt2436_22_09_2017.html>.Acesso em: 12/03/2021.

MINISTÉRIO DA SAÚDE. Novos dados reforçam a importância da prevenção do suicídio. 2018, Brasília, DF. Disponível em: < https://www.saude.gov.br/noticias/agencia-saude/44404-novosdados-reforcam-a-importancia-da-prevencao-do-suicidio >. Acesso em: 25/05/2020.

ORGANIZAÇÃO MUNDIAL DE SAÚDE. PREVENÇÃO DO SUICÍDIO: UM MANUAL PARA PROFISSIONAIS DA SAÚDE EM ATENÇÃO PRIMÁRIA. 2000, Genebra. Disponível em: < https://www.who.int/mental_health/prevention/suicide/en/suicideprev_phc_port.pdf $>$. Acesso em: $14 / 03 / 2021$.

Um suicídio ocorre a cada 40 segundos no mundo, diz

OMS. 2019. Disponível em: < https://nacoesunidas.org/um-suicidio-ocorre-a-cada-40-segundos-nomundo-diz-oms/ >. Acesso em: 14/03/2021.

UNIVERSIDAde ABERTA DO SUS. PREVENÇÃO AO SUICÍDIO. 2020, UFSC, Santa Catarina. Disponível em: $<$ https://unasus-quali.moodle.ufsc.br/course/view.php?id=56 > . Acesso em: $15 / 03 / 2021$. 